\section{Systematic review of Purtscher's and Purtscher-like retinopathies}

\begin{abstract}
Purpose (1) To describe the clinical characteristics of Purtscher and Purtscher-like retinopathies, including etiologies, fundoscopic signs, results of complementary investigation, treatments, and outcomes.

(2) To compare visual acuity (VA) of patients receiving corticosteroids for PuR compared with observation.

Methods Systematic review of several databases (1980-2010): Medline, EMBASE, ISI, EBSCO, Science Direct and Google

Scholar. Study selection criteria included: (A)

Studies of PuR with ophthalmology assessments; (B) $\geq 3$ of 5 diagnostic criteria of PuR; (C) Quantified VA at presentation. For quantitative assessment (purpose 2), we selected only studies that reported whether corticosteroids were administered, and with vision assessments after at least 1 month.
\end{abstract}

Results (1) From 670 studies initially found, 40 were included (68 cases, 110 eyes): 1 prospective, 5 case series, and 34 case reports. Mean VA at presentation was $1.3 \log$ MAR (logarithm of the minimum angle of resolution) ( $<20 / 200$; range: $20 / 20$-light perception). Purtscher flecken were underreported. Trauma and acute pancreatitis were the most frequent etiologies. There were six deaths, all with systemic associations. (2) There was no statistically significant difference between VA improvement for patients treated with corticosteroids compared with observation. Visual prognostic factors identified included etiology (pancreatitis and trauma were associated with higher probability of visual improvement) and male gender.

Conclusion Due to limitations of case reports and series, the presented data are only useful as broad characterizations of the clinical course of PuR. Further studies, possibly including trials to assess the effectiveness of corticosteroids use, and larger prospective cohort studies, are
AIM Miguel ${ }^{1,2}$, F Henriques' ${ }^{1}$, LFR Azevedo², AJR Loureiro ${ }^{1}$ and DAL Maberley ${ }^{3}$

necessary, but may not be feasible to conduct.

Eye (2013) 27, 1-13; doi:10.1038/eye.2012.222;

published online 23 November 2012

Keywords: corticosteroids; Purtscher's retinopathy; Purtscher-like retinopathy; systematic review

\section{Introduction}

Purtscher's retinopathy is an occlusive microvasculopathy associated with trauma. It was first described in 1910 by Otmar Purtscher ${ }^{1}$ in a middle-aged man who fell off a tree and suffered cranial trauma. There is some doubt about the incidence of this pathology; authors have estimated its incidence at 0.24 persons per million per year (including Purtscher and Purtscher-like retinopathies) ${ }^{2}$ while others believe that the incidence is higher because the condition may frequently be asymptomatic. ${ }^{3}$ Bilaterality is present in up to $60 \%$ of cases.

Purtscher's retinopathy generally occurs as a result of cranial trauma or thoracic compression. When there is a non-traumatic etiology, the correct designation is Purtscher-like retinopathy. Frequent causes of Purtscher-like retinopathy include acute pancreatitis, renal failure, and autoimmune disease. Purtscher-like retinopathy in acute pancreatitis is an indicator of multiorgan failure and is often associated with a fatal outcome. ${ }^{3}$

The diagnosis of Purtscher's and Purtscherlike retinopathies (PuR) is clinical, with a presentation that usually includes sudden vision loss of variable severity, hours to days after the causal pathology. Fundoscopic signs include cotton-wool spots and intraretinal hemorrhages, described in $83-92 \%$ of a series of cases. ${ }^{4}$ Purtscher flecken are considered to be pathognomonic, ${ }^{4}$ but occur in only $50 \%$ of cases.
${ }^{1}$ Ophthalmology

Department, Central University Hospital of Coimbra, Coimbra, Portugal

${ }^{2}$ Department of Health Information and Decision Sciences, Center for Research in Health Technologies and Information Systems (CINTESIS), Faculty of Medicine, University of Porto, Porto, Portugal

${ }^{3}$ Retinal Division, Department of Ophthalmology and Visual Sciences, University of British Columbia, Vancouver, British Columbia, Canada

Correspondence: AIM Miguel, Rua Quinta do Sardoal, VE 3, n¹0, 4430-182 Vila Nova de Gaia, Portugal. Tel: + 351932482477. E-mail: myworld_ana@ hotmail.com

Received: 7 March 2012 Accepted in revised form: 2 October 2012 Published online: 23 November 2012 
It is widely assumed that the flecken are the result of occlusion of the precapillary arterioles. The characteristic finding is intraretinal whitening but with a clear zone (within $50 \mu \mathrm{m}$ ) on either side of the retinal arterioles, venules, and precapillary arterioles. This is in contrast to cotton-wool spots, which have ill-defined edges, ${ }^{4,5}$ and are located superficially over vessels. Fluorescein angiography may show leakage of dye from retinal arterioles, capillaries, and venules in patients with relatively mild Purtscher's retinopathy. Arteriolar obstruction is noted in more severe cases. There are many theories about pathogenesis but typically Purtscher's microangiopathy is thought to be due to precapillary occlusion, due to fat emboli, leukoaggregation, or other mechanisms.

Treatment is variable with some physicians observing expectantly and others primarily administering corticosteroids. There have been non-systematic reviews of Purtscher's retinopathy; ;,7 however, no recent systematic review has been performed. There is a need for an updated systematic review of Purtscher's retinopathy given ongoing controversies regarding treatment, and due to further published cases since prior reviews.

We present a systematic review of Purtscher's retinopathy and Purtscher-like retinopathies. Part one of this review will describe the clinical characteristics of PuR, namely: clinical presentation, causal/associated pathologies, results of diagnostic testing, treatments performed, and clinical outcomes.

In part two of this review, our goal is to assess visual acuity (VA) changes of patients receiving corticosteroids compared with those without treatment (main outcome). Secondary comparisons between groups include an assessment of clinical changes and prognostic factors.

\section{Materials and methods}

\section{Search methods}

The search methodology was guided by the Cochrane Collaboration's recommendations. ${ }^{8}$ Two independent reviewers, $\mathrm{AM}$ and $\mathrm{FH}$, examined each title and abstract to exclude obviously irrelevant reports. They then independently examined the full text of each article to determine eligibility according to the noted selection criteria below. Disagreements were solved by consensus and registered to allow assessment of reliability using the kappa statistics.

Electronic searches included the following databases: Medline (via Pubmed)—1950 to May 2010, EMBASE1974 to May 2010; ISI-2000 to May 2010, and other databases via EBSCO, Science Direct, and Google Scholar. We also searched clinicaltrials.gov and Current
Controlled Trials (in www.controlled-trials.com).

The search query for Pubmed was '(Purtscher[tiab] OR Purtscher-like[tiab] OR angiopat*[tiab]) AND retinopath*[tiab]'; similar searches were adjusted to each database. All searches were made from 1 to 4 May 2010. No publication date or language exclusions were made. We also hand-searched reference books, journals, and bibliographies from relevant papers. We mailed (or sent letters) to experts in the field for help in identifying the unpublished data and gray literature to avoid publication bias.

\section{Selection criteria}

Inclusion criteria were

- Case reports, case series or trials meeting predetermined quality criteria, based on the Cochrane Collaboration, ${ }^{8}$ STARD, ${ }^{9}$ and STROBE. ${ }^{10}$

- Patients that matched at least three of five diagnostic PuR criteria (adapted from several papers ${ }^{4,7,8}$ ):

1. Purtscher flecken

2. Retinal hemorrhages, low-to-moderate number (1-10)

3. Cotton-wool spots (typically restricted to posterior pole)

4. Probable or plausible explanatory etiology

5. Complementary investigation compatible with diagnosis

- Quantified VA at presentation.

- Follow-up by an ophthalmologist with fundoscopic evaluation, at least one month after initial diagnosis.

For the assessment of corticosteroid efficacy in PuR, we only included studies that fulfilled another two inclusion criteria: studies with follow-up at 1 month (with all assessments and VAs registered), and studies reporting whether corticosteroids were administered (if studies did not explicitly note corticosteroids use for each patient, then they were excluded).

Exclusion criteria included: duplicate reports, studies without follow-up, and studies without examinations performed by an ophthalmologist. To avoid language bias, publication language was not an exclusion criteria.

\section{Data collection and analysis}

Two reviewers, AM and FH, independently collected data and assessed quality. A form was developed specifically for this project to assist in consistent data collection from each study. This form included: year of publication, author's name, as well as each subject's age, gender, retinal pathology, etiology of retinopathy, and laterality, VA at presentation $\left(\mathrm{VA}_{0}\right)$; VA at 1 month $\left(\mathrm{VA}_{1}\right)$; 
VA at 2 months $\left(\mathrm{VA}_{2}\right)$; VA at 6 months $\left(\mathrm{VA}_{6}\right)$, diagnostic criteria of PuR, signs and results of tests, and treatment (including dosing and administration route). The investigators had clear coding instructions.

If VA was not recorded in the logarithm of the minimum angle of resolution (logMAR) scale, ${ }^{11}$ then it was converted. Snellen VA scores were converted to the $\log$ MAR for statistical analyses, using the calculation: $\log$ MAR value $=\log 10(1 /$ Snellen $)$. VA scores below Snellen 20/400 were assigned as counting fingers ( $\log$ MAR value of 1.7$)$, hand motion ( $\log$ MAR value of $2.5)$, and light perception ( $\log M A R$ value of 3.0). Where necessary, authors were contacted by E-mail ${ }^{4,12-32}$ or letter ${ }^{1,32}$ to provide further data (some responses were received ${ }^{12,14,17}$ ). Some studies required translation. ${ }^{15,20,33-40}$

Quality evaluation graphs were made using Review Manager v5 (Cochrane Collaboration, Oxford, UK). Data were collected as part of the quality evaluation process: description of the study design, description of patient demographics, diagnostic criteria used to define PuR, VA testing method, description of results, follow-up examinations made by an ophthalmologist, and followup duration.

\section{Quantitative data synthesis}

All analyses were performed using Excel for simple calculations or SPSS (SPSS Inc., version 17.0, Chicago, IL, USA). Disagreements regarding study inclusion were calculated using kappa statistics.

Subgroup analyses previously planned were performed: corticosteroid use vs no use; presence/ absence of associated pathology.

We tried to identify prognostic factors associated with VA improvement, using Fisher's exact test for categorical variables, including: etiology of PuR, gender, bilaterality, presence or absence of Purtscher flecken, presence or absence of retinal edema, and results of complementary tests. Results and features of complementary tests searched included: (1) fluorescein angiography (nonperfusion, early hypofluorescence, delayed filling, peripapillary staining, generalized ischemia, and abnormalities present after 1 month); (2) OCT (retinal edema, atrophy after 1 month); (3) visual field (scotoma, visual field alterations after 1 month); (4) visual evoked potentials changes; and (5) Electroretinogram changes.

Univariate analyses of normally distributed continuous variables were performed using Student's t-test. Independent samples Mann-Whitney test was used for continuous variables without normal distribution (all variables were tested for normality using Kolmogorov-Smirnov test). Since there were cases of bilateral Purtscher, we ran three separate analyses: analysis of each involved eye ('all-eyes'), comparison of eyes with best VA ('best-eye'), and worst VA ('worsteye'). Best eye and worst eye analyses included cases of unilateral PuR. Significance was accepted at 0.05 .

\section{Results}

The Pubmed search yielded 232 studies; EMBASE yielded 169 results; ISI 89, EBSCO 90 and Google Scholar and hand searching yielded 90 articles. Of the total 670 articles, 65 studies were selected for a full-text review (Figure 1). For study inclusion, kappa was 0.88 (good agreement). In all, 40 studies that included 68 cases (involving 110 eyes) were included for our descriptive review; and 23 studies (with 24 cases and 35 eyes) were included for the quantification of VA improvement and response to corticosteroid therapy.

\section{Demographic details}

Characteristics of included studies. The characteristics of the 40 included studies are summarized in Table 1. Most studies were case reports, although some were case series and one was a prospective study. ${ }^{2}$

Characteristics of patients. The mean patient age was 34 years (minimum 11 weeks and maximum 76 years) and $60 \%$ were male. The mean time of follow-up was 20.3 months (with a minimum of 30 days and maximum of 96 months).

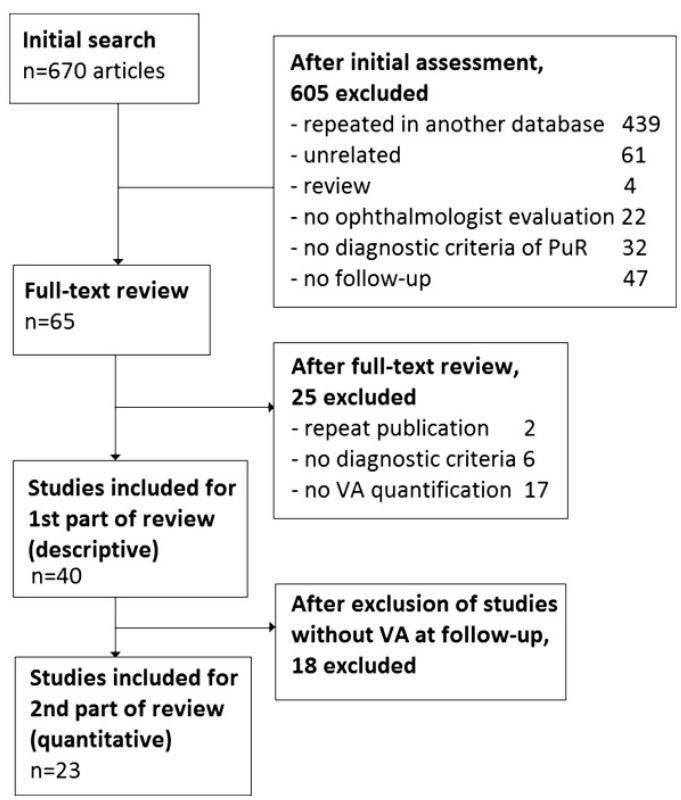

Figure 1 Flowchart of search strategy. 


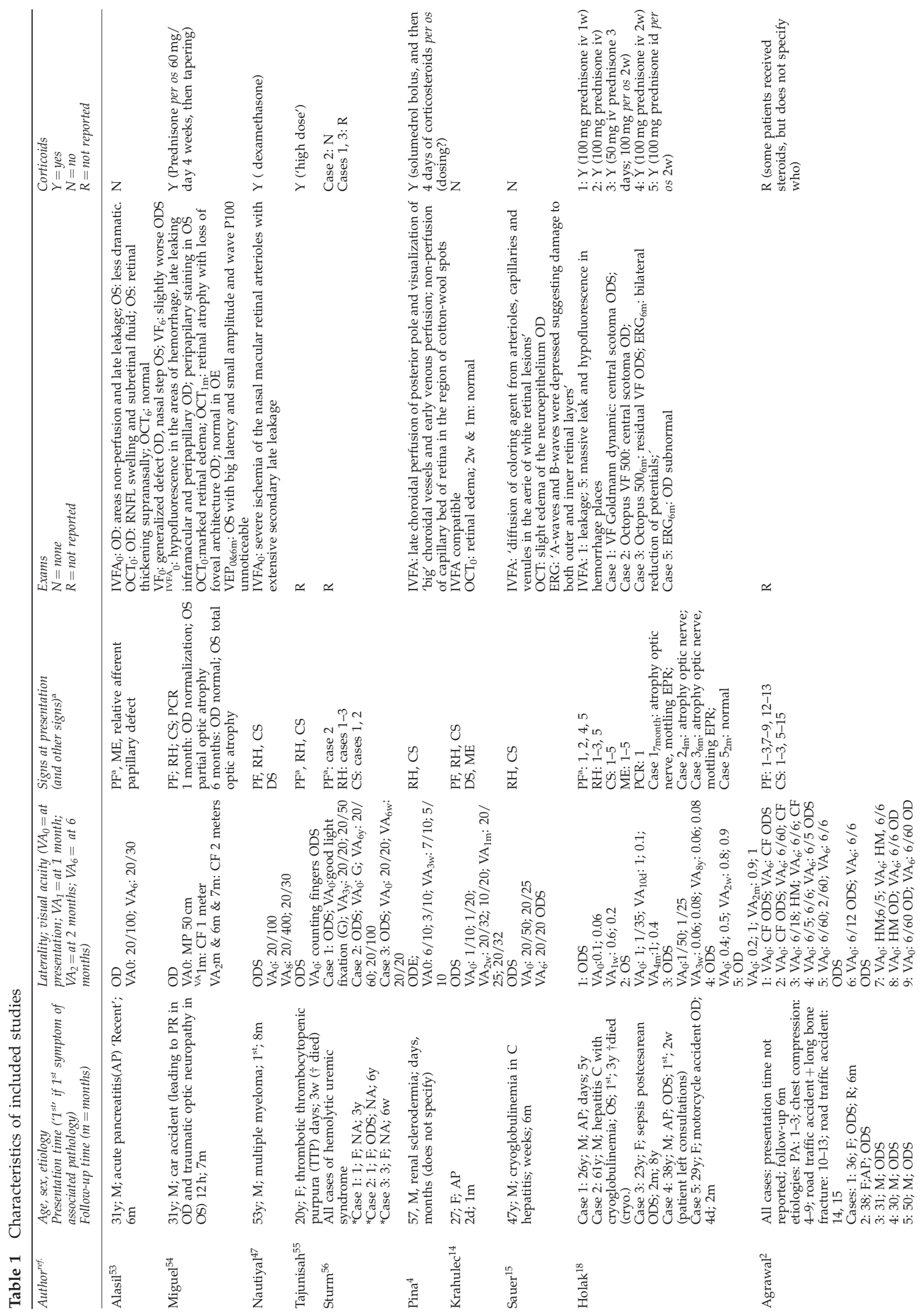




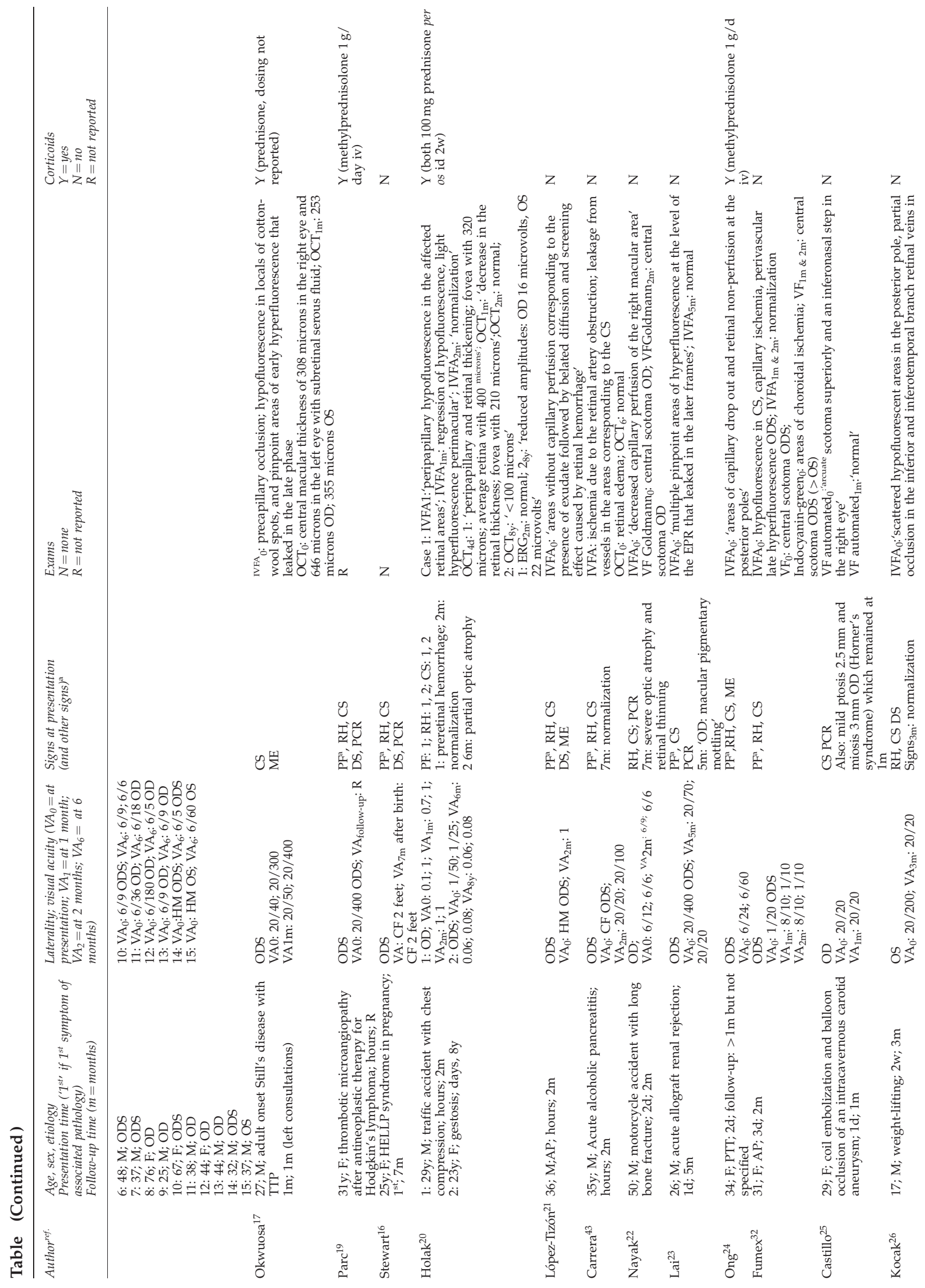




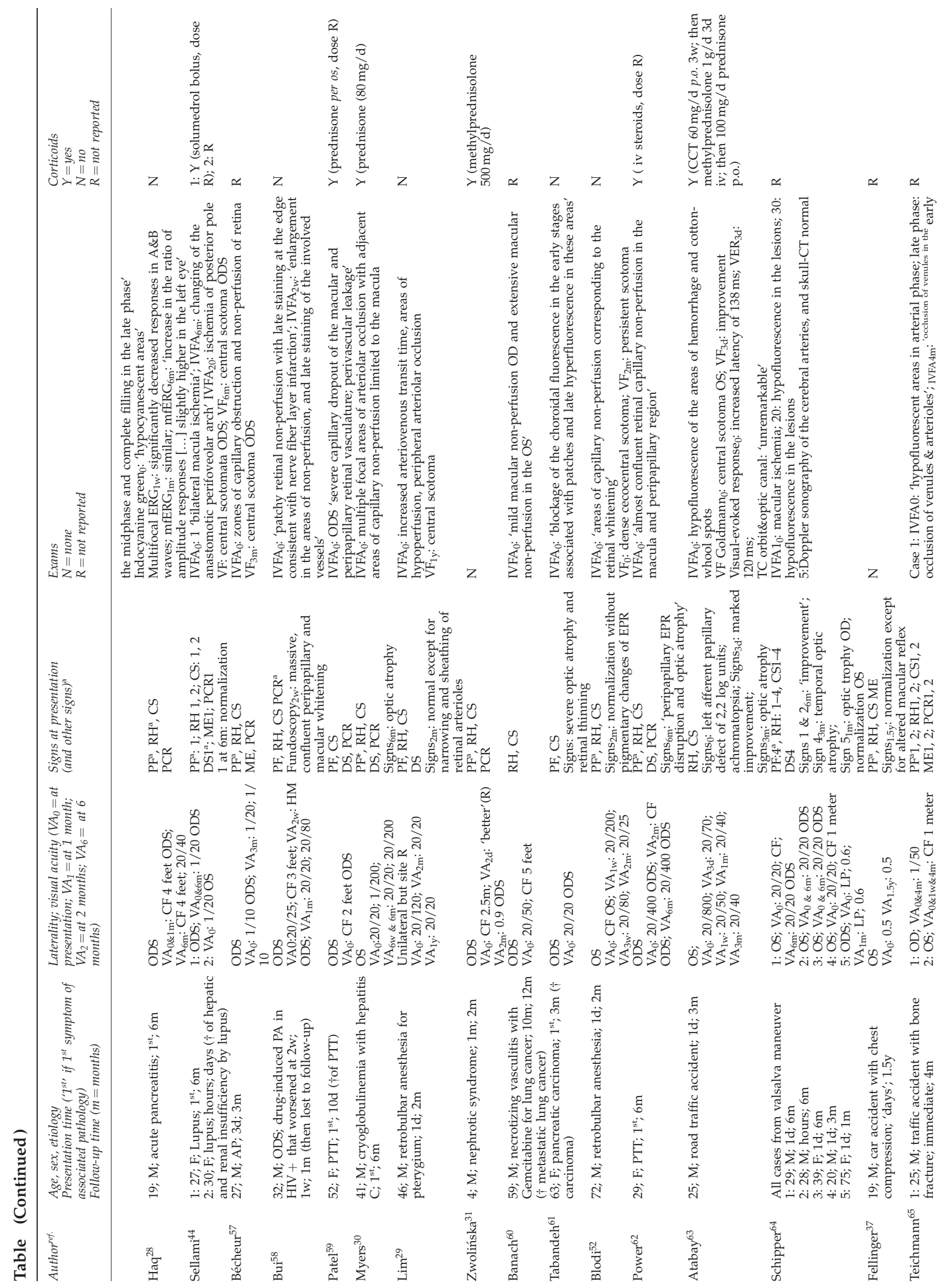




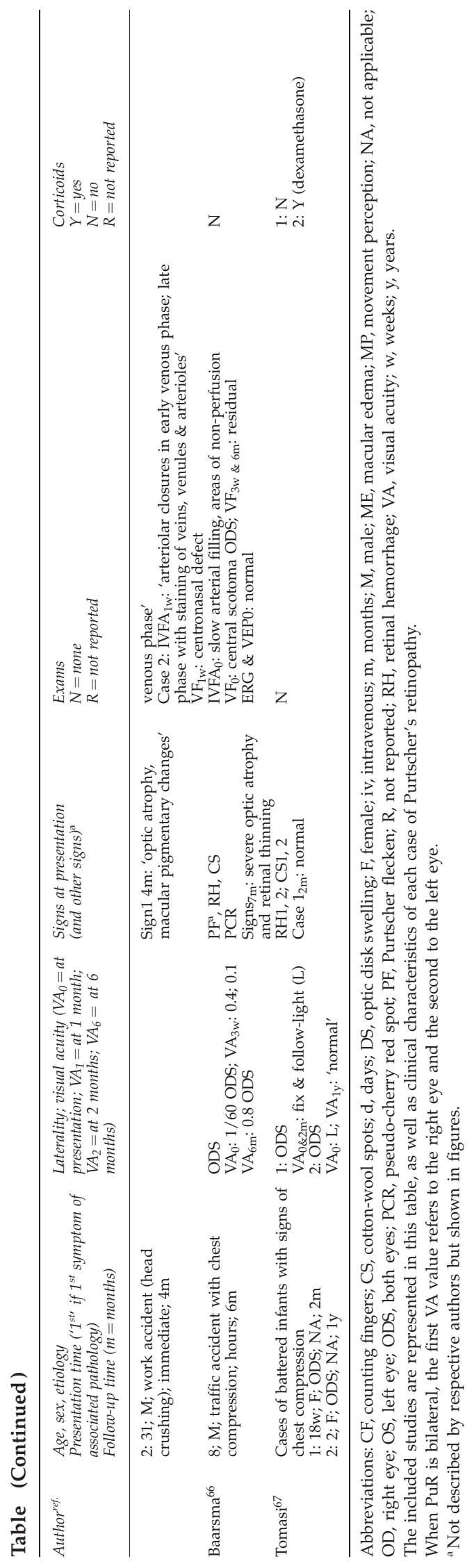

\section{Systemic associations of PuR}

Table 2 presents the relative frequency of associated pathology in each patient with PuR; the most frequent being trauma, followed by acute pancreatitis. Death occurred in 6 (out of $68 \mathrm{PuR}$ cases) patients, 2 with thrombotic thrombocytopenic purpura (TTP), of 5 cases of TTP. Of those five patients with TTP, only one had unilateral involvement. All cases related to pregnancy and TTP were bilateral. Only one case of acute pancreatitis had unilateral Purtscher-like retinopathy.

\section{Clinical signs of PuR at baseline and follow-up}

The most frequently encountered signs of PuR were cotton-wool spots which occurred in 63/68 (93\%) of cases, followed by retinal hemorrhages $(44 / 68,65 \%)$, and by Purtscher flecken $(43 / 68,63 \%)$.

Of the 43 cases with Purtscher flecken, 8 were correctly reported (Purtscher flecken were reported and a picture was presented with that sign), 22 cases were not reported by authors but identified during image assessments by reviewers as part of this study, and 13 cases were reported but no photograph was provided. Ten cases presented a picture without Purtscher flecken and correctly did not report it. Fifteen cases had no report of Purtscher flecken and did not present a photograph.

Occasionally, there were other signs at presentation, such as macular edema (22\%), optic disk swelling (16\%), and a pseudo cherry red spot (26\%).

Fundoscopic findings after 2 months follow-up were reported in 22 cases and included: normalization of the retinal appearance $(9 / 22,40 \%)$, optic atrophy $(14 / 22$, $64 \%)$, mottling of the retinal pigment epithelium $(5 / 22$, $23 \%)$, retinal thinning $(3 / 22,14 \%)$, and narrowing of retinal arteries $(1 / 22,4 \%)$. Some cases had several signs (the most frequent combination was optic atrophy with mottling of retinal pigment epithelium).

Fluorescein angiography was performed in 31 cases (45.5\% of patients and showed: areas of non-perfusion $(22 / 31,70 \%)$, retinal ischemia $(22 / 31,70 \%)$, early hypofluorescence $(6 / 31,20 \%)$, slower filling of vessels $(14 / 31,45 \%)$, late leakage $(6 / 31,20 \%)$, peripapillary staining $(5 / 31,16 \%)$, and precapillary occlusion $(2 / 31$, $6.7 \%)$.

Ocular coherence tomography (OCT) was performed in eight cases at presentation and showed retinal edema in seven cases and slight thickening in the other case. OCT findings after 1 month were performed in seven cases showing normalization in five cases and macular atrophy in two cases (both with severe macular edema at presentation).

Visual field tests were performed at presentation in 14 cases: 13 showing a central scotoma (93\%), of which 
Table 2 Etiologies of PuR

\begin{tabular}{|c|c|c|c|c|c|c|}
\hline Associated pathology & $\begin{array}{l}\text { Frequency } \\
\text { (number of } \\
\text { cases) }\end{array}$ & $\begin{array}{c}\text { Relative } \\
\text { frequency } \\
(\%)\end{array}$ & $\begin{array}{l}\text { Bilaterality } \\
\quad(\%)\end{array}$ & Reported death & $\begin{array}{c}\text { Mean VA at } \\
\text { presentation } \\
\text { (logMAR) }\end{array}$ & $\begin{array}{c}\text { Mean VA at } 6 \\
\text { months (logMAR) }\end{array}$ \\
\hline Trauma & 23 & 33.8 & $12(52.2 \%)$ & 0 & 1.48 & 0.90 \\
\hline Acute pancreatitis & 13 & 19.1 & $12(92.3 \%)$ & 0 & 1.51 & 0.40 \\
\hline Valsalva maneuver & 6 & 8.8 & $1(16.6 \%)$ & 0 & 0 & 0 \\
\hline $\begin{array}{l}\text { Thrombotic thrombocytopenic } \\
\text { purpura }\end{array}$ & 5 & 7.3 & $5(100 \%)$ & $\begin{array}{l}2 \text { (both with } \\
\text { bilateral } \\
\text { involvement) }\end{array}$ & 1.43 & 1.70 \\
\hline Hemolytic uremic syndrome & 3 & 4.4 & 3 & 0 & 0 & 0.50 \\
\hline Cryoglobulinemia in hepatitis C & 3 & 4.4 & 3 & $\begin{array}{c}1 \text { (bilateral } \\
\text { involvement) }\end{array}$ & 1.38 & 0.50 \\
\hline $\begin{array}{l}\text { Pregnancy related (HELLP, sepsis } \\
\text { post-cesarean and gestosis) }\end{array}$ & 3 & 4.4 & $3(100 \%)$ & 0 & 1.90 & 1.65 \\
\hline Lupus & 2 & 3 & $1(50 \%)$ & 1 (unilateral) & 1.70 & 1.70 \\
\hline Retrobulbar anesthesia & 2 & 3 & $0(0 \%)$ & 0 & 1.25 & 0 \\
\hline Pancreatic carcinoma & 1 & 1.5 & 1 & 1 (bilateral) & 0 & $\begin{array}{l}\text { NA (0 at } 3 \\
\text { months) }\end{array}$ \\
\hline $\begin{array}{l}\text { Thrombotic microangiopathy } \\
\text { after antineoplastic use }\end{array}$ & 1 & 1.5 & $1(100 \%)$ & 0 & 1.43 & Not reported \\
\hline $\begin{array}{l}\text { Necrotizing vasculitis with lung } \\
\text { cancer }\end{array}$ & 1 & 1.5 & $1(100 \%)$ & 1 (bilateral) & 1 & Not reported \\
\hline Acute allograft rejection & 1 & 1.5 & $1(100 \%)$ & 0 & 1.70 & $\begin{array}{l}\text { NA }(0.30 \text { at } 5 \\
\text { months })\end{array}$ \\
\hline Renal sclerodermia & 1 & 1.5 & $1(100 \%)$ & 0 & 0.15 & $\begin{array}{l}\text { NA ( } 0.20 \text { at } 1 \\
\text { month) }\end{array}$ \\
\hline Nephrotic syndrome & 1 & 1.5 & $1(100 \%)$ & 0 & 1.70 & $\begin{array}{l}\text { NA }(0.90 \text { at } 2 \\
\text { months) }\end{array}$ \\
\hline Multiple myeloma & 1 & 1.5 & $1(100 \%)$ & 0 & 0.70 & 0.40 \\
\hline $\begin{array}{l}\text { Coil embolization of } \\
\text { intracavernous carotid aneurism }\end{array}$ & 1 & 1.5 & $0(0 \%)$ & 0 & 0 & $\begin{array}{l}\text { NA }(0 \text { at } 1 \\
\text { month) }\end{array}$ \\
\hline
\end{tabular}

Abbreviations: VA, visual acuity; NA, not available.

Characteristics of etiologies of Purtscher and Purtscher-like retinopathies are presented.

2 cases had also a nasal step and another had an arcuate scotoma and nasal step. Further visual field testing after 1 month of follow-up was performed in 11 cases, with normalization in 1 case, scotoma enlargement in 1 case, persistent defect in 6 cases, and partial improvement in the remaining 3 cases.

Visual evoked potentials were performed in three cases, showing increased latency and decreased amplitude of responses (two cases) or no alteration (one case); after 1 month, one case improved partially and the other did not. Electroretinogram was performed at presentation in two cases, both demonstrating depression of the $a$ and $b$ waves. Electroretinogram after first month of follow-up was performed in five cases (including the two studied at baseline): one showed normalization, one showed persistent defect; the remaining (not studied at baseline) showed subnormal results.

\section{Risk of bias assessment}

We performed a quality evaluation/general risk of bias assessment of all studies; however, we present results of

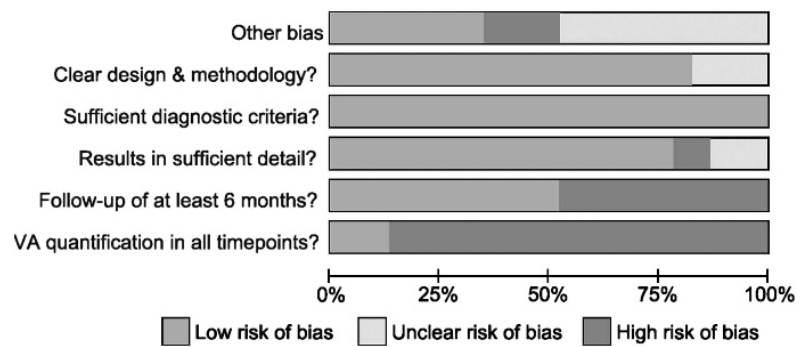

Figure 2 Risk of bias graph.

only the studies included for quantitative analysis to identify and reduce methodological heterogeneity.

In Figure 2, we present the summary of our quality evaluation of included studies, according to each parameter assessed-risk of bias graph. Most studies had low risk of bias in the description of results but not in the quantification of VA. In fact, there was a high risk of bias in VA quantification (at 1, 2, and 6 months), which adds heterogeneity. Few studies reported strategies to prevent selection bias, information bias, or other bias. Risk of bias 
in each study for each of those variables can be requested to the corresponding author.

\section{Quantitative analysis}

VA is reported at 1, 2, and 6 months because almost all studies reported those time points. Studies that did not report corticosteroid use or that had a follow-up of $<1$ month were excluded. Consequently, of 40 studies that were included in the descriptive review (purpose 1), only 24 cases (from 23 studies) were selected for quantitative analysis (purpose 2). From these, 12 cases reported VA at 1 month, 10 cases reported VA at 2 months, and 11 cases reported VA at 6 months (final VA).

VA at presentation and after follow-up. According to our 'best-eye' analysis, mean VA at presentation was 1.5 $\log$ MAR (equivalent to $<20 / 200$ ) with standard deviation of 0.75 ; this value had extreme variability (20/ 20 to light perception). Our 'worst-eye' analysis showed similar values. In the 'best-eye' analysis, the mean final VA improvement was $0.85 \log$ MAR (equivalent to 0.13 in decimal scale) with standard deviation of 0.82 ; in 'worsteye' was $0.96 \log \mathrm{MAR}(\mathrm{SD}=0.80)$; in 'all-eyes' was 0.91 $\log \mathrm{MAR}(\mathrm{SD}=0.86)$.

VA according to associated pathology. VA at presentation according to etiology is represented in Figure 3. Cases associated with Valsalva and coil-embolization of carotid aneurism $^{25}$ presented with the best VA $(\log$ MAR $=0)$, while cases of PuR associated with pregnancy or lupus presented the worst (respectively 1.90 and 1.70 $\log$ MAR).

The highest VA mean improvement occurred in acute pancreatitis (1.23 logMAR; $\mathrm{SD}=1.10)$ and in trauma (1.35 $\log \mathrm{MAR} ; \mathrm{SD}=0.78)$

\section{VA improvement in corticosteroid vs no corticosteroid} use. There was no statistically significant difference in VA improvement between patients receiving corticosteroids vs no corticosteroids, at 1, 2, or 6 months of follow-up (Fisher's exact test, $P=0.332$ at 6 months in 'best-eye' analysis; $P=0.356$ in 'all-eyes'; $P=1$ in 'worsteye').

Bilateral Purtscher retinopathy. There was no statistically significant difference between VA or VA improvement of left or right eye, at presentation, at 1 month, at 2 months, or at 6 months of follow-up (2 related samples nonparametric $t$-test) in the 14 bilateral cases.

Prognostic factors. There were six deaths among all cases. Systemic etiologies with fatal outcomes were cancer (two deaths in two patients), thrombotic thrombocytopenic purpura (two deaths in five patients), cryoglobulinemia (one death in three patients), and

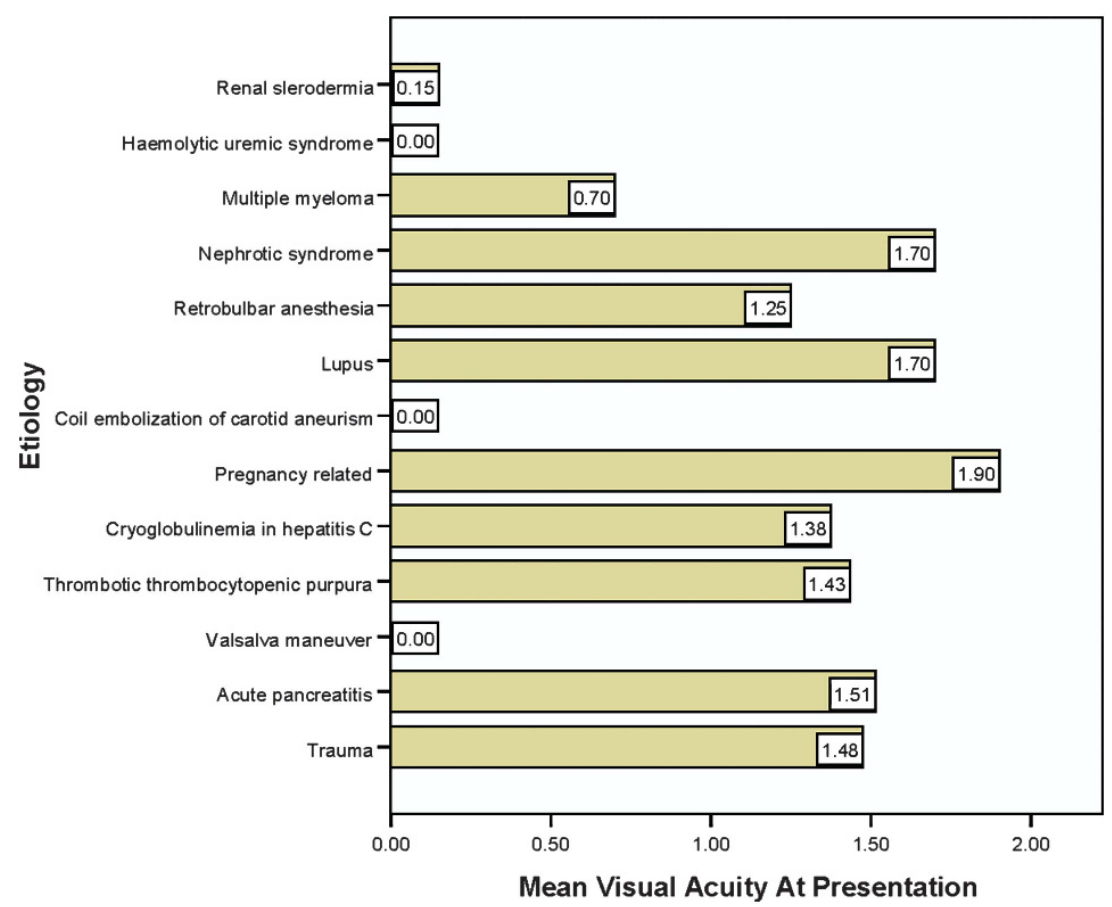

Figure 3 Mean visual acuity at presentation according to etiology. In logMAR scale, 0 is equivalent to normal VA; the higher the value of $\log M A R$, the worse is VA. 
lupus (one death in two patients). Death was not associated with initial VA (Mann-Whitney test for initial VA vs death). Five of these deaths occurred within 3 weeks of PuR diagnosis.

As for prognostic factors for VA improvement, we identified, in the 'best-eye' analysis male gender was associated with better VA improvement at 2 months $(P=0.018$, Fisher's exact test $)$ and at 6 months $(P=0.041$, Fisher's test) but not at 1 month $(P=0.333)$. This was similar for the 'worst-eye' analysis $\left(P_{2}\right.$ months $=0.036$; $\left.P_{6 \text { months }}=0.038\right)$ and 'all-eyes' $\left(P_{2}\right.$ months $=0.011$; $\left.P_{6 \text { months }}=0.004\right)$ analyses.

Etiology of PuR may be associated with VA improvement at 1 month and 2 months, particularly in trauma and acute pancreatitis ('best-eye' with Fisher's test with $P=0.010$ and $P=0.002$, respectively) but not with VA improvement at 6 months. Results were similar for 'worst-eye' $\left(P_{1 \mathrm{~m}}=0.015 ; P_{2 \mathrm{~m}}=0.515 ; P_{6 \mathrm{~m}}=0.612\right)$ and 'all-eyes' $\left(P_{1 \mathrm{~m}}=0.001 ; P_{2 \mathrm{~m}}=0.294 ; P_{6 \mathrm{~m}}=0.140\right)$ analyses.

According to 'all-eyes' analysis (but neither 'best-eye' nor 'worst-eye'), absence of macular edema was associated with higher VA improvement at 2 months $(P=0.029$; but neither at 1 nor at 6 months); and absence of pseudo cherry red spot with better VA improvement at 6 months $(P=0.017)$.

Poor prognostic factors for visual improvement such as choroidal hypoperfusion, optic disc swelling, ${ }^{7}$ or massive Purtscher flecken ${ }^{18}$ were not statistically significant, but only a small number of cases presented with these findings.

\section{Discussion}

This systematic review provides an up-to-date, comprehensive assessment of the literature regarding Purtscher's retinopathy. Efforts have been made to build a comprehensive, quantitative assessment of the available data, which is of relatively low quality.

Purtscher flecken were reported in $23 \%$ but were visible in $63 \%$ of the fundus images available in each report (identified by reviewers). The relatively poor identification of Purtscher flecken by authors of included papers suggests that attention should be paid to recognize and document this particular characteristic of $\mathrm{PuR}$, since it is pathognomonic. On the other hand, this particular sign is not of prognostic value.

Visual prognostic factors identified included etiology (pancreatitis and trauma associated with higher probability of visual improvement). Male gender was also a good prognostic factor; however, this may be due to higher preponderance of males in etiologies of good prognostic value (like trauma); we had insufficient power to run a subgroup analysis to clarify this issue.
Unlike other studies that discussed prognostic factors for $\mathrm{PuR},{ }^{18}$ we did not find any fundoscopic or angiographic sign of prognostic value for VA improvement.

Only one third of the initial studies presented VA data after follow-up. We would like to emphasize the importance of reporting clinical signs and VA in future studies of PuR not only for the time of presentation but also after follow-up, to better understand the behavior of this pathology over time.

Limitations of this review include the preponderance of clinical cases and series from which our data were derived. In spite of the quality evaluation performed for each study, in case reports there is no unified methodology, which limits the comparability. In the case of VA, not all studies reported vision at consistent time points, as a result, all of these values are considered to be an estimate. On the other hand, in rare pathologies such as PuR in which there are no trials, a systematic review of clinical cases is a valid adapted methodology.

In addition, there may be publication bias and misclassification bias among the included studies. Therefore, the value of our quantitative analysis is limited and should be interpreted with caution. Nonetheless, there certainly appears to be a definite trend toward improved vision within the first 2 months following onset of Purtscher's.

As previously stated, it is agreed that diagnosis of PuR is clinical, being confirmed by angiography. However, the biologic mechanism of injury remains uncertain.

Histopathological studies show signs of retinal vascular occlusion with edema of retinal internal layers, subretinal cystoid space, and abrupt transition to normal retina. 5,41

There are several theories that have been forwarded since the initial mechanical theory. ${ }^{1}$ The most currently accepted is microembolization, causing arteriolar precapillary occlusion and microvascular infarct of retinal nerve fiber layer, forming cotton-wool spots. ${ }^{5,7,16}$ This could be due to a fat emboli (typically described in long bone fracture ${ }^{42}$ ) or due to pancreatic proteases in systemic circulation (typically described in acute pancreatitis $^{34,43}$ ).

Leukoembolization by leukocytary aggregation and C5 complement activation with secondary lymph extravasation ${ }^{7,44}$ is another proposed mechanism (also supported by some experimental studies ${ }^{45}$ ). Other pathogenic processes that may be involved include capillary endothelial damage (supported by late leakage in IVFA ${ }^{16}$ ), sudden increase of intracranial pressure (causing precapillary occlusion in lamina crivosa ${ }^{43,46}$ ), sudden expansion of retinal veins, ${ }^{7}$ or hyperviscosity (such as in multiple myeloma ${ }^{47}$ ). A recent study used computer dynamic flow simulations and suggested an additional mechanism: an inner layer retinal posterior 
pole rheological event that results in vascular endothelial dysregulation. ${ }^{48}$ Probably, these mechanisms are not mutually exclusive and there is some overlap in the final mechanism: precapillary arterioles occlusion by altered retinal microvascular permeability. ${ }^{2-4,7}$

Regarding treatment, several articles and reviews such as our own did not find corticosteroid treatment associated with a statistically significant improvement in outcome. ${ }^{1,2,5}$ Observation and treatment of the underlying etiology may be the most reasonable therapeutic option without risk of adverse drug effects. However, since some case reports showed hastened visual recovery after corticosteroids use, ${ }^{2,49}$ further information is needed to determine if corticosteroids can or cannot change the natural history of a patient with Purtscher's retinopathy. Visual improvement in those cases has been attributed to the ability of corticosteroids to stabilize damaged neuronal membrane and microvascular channels, and to inhibit granulocyte aggregation related to complement activation. 7,50

Eventually, a trial (preferably masked) with corticosteroids in PuR could be considered to end controversies about the need of this treatment. Preferably, a natural history cohort study might be the most reasonable first step. The biggest barrier to any prospective study design is the small frequency of this pathology, estimated as 0.24 per million. ${ }^{2}$ Ultimately, a National or International Study might be necessary.

Also, to estimate the real incidence and to identify asymptomatic cases of PuR (which are of relatively high frequency ${ }^{3,51}$ ), more screening should be done in patients identified to be at risk. This study may assist in the identification of such individuals. In all cases, evaluation by an ophthalmologist is essential. Follow-up is crucial as well, and should have defined timelines (we suggest measuring VA at presentation, at 1 month, at 2 months, and at 6 months) using a standard methodology. We recommend diagnostic criteria for Purtscher's retinopathy (similar to the one used by Agrawal ${ }^{2}$ and adapted by us).

\section{Conflict of interest}

The authors declare no conflict of interest.

\section{Acknowledgements}

We would like to thank MSD for obtaining the full text of 9 articles, and Théa for obtaining the full text of 21 articles.

\section{References}

1 Purtscher O. Noch unbekannte befunde nach schadeltrauma. Ber Dtsch Ophthalmol Ges 1910; 36: 294-301.
2 Agrawal A, McKibbin M. Purtscher's retinopathy: epidemiology, clinical features and outcome. Br J Ophthalmol 2007; 91(11): 1456-1459.

3 Holló G. Frequency of Purtscher's retinopathy. $\mathrm{Br} J$ Ophthalmol 2008; 92(8): 1159.

4 Proença Pina J, Ssi-Yan-Kai K, de Monchy I, Charpentier B, Offret $\mathrm{H}$, Labetoulle M. Purtscher-like retinopathy: case report and review of the literature. J Fr Ophtalmol 2008; 31(6): 609.

5 Kincaid MC, Green WR, Knox DL, Mohler C. A clinicopathological case report of retinopathy of pancreatitis. Br J Ophthalmol 1992; 66(4): 219-226.

6 Medeiros HA, Medeiros JA, Caliari LC, Silva J. Purtscher's and Purtscher-like retinopathies. Rev Bras Oftalmol 2009; 68(2): 114-119.

7 Agrawal A, McKibbin M. Purtscher's retinopathies: a review. Surv Ophthalmol 2006; 51: 129-136.

8 Higgins JPT, Green S (eds). Cochrane Handbook for Systematic Reviews of Interventions, Version 5.0.0 26th Vol (John Wiley \& Sons: Chichester (UK), 2008; 434-449.

9 Bossuyt PM, Reitsma JB, Bruns DE, Gatsonis CA, Glasziou PP, Irwig LM et al. STARD group. Toward complete and accurate reporting of studies of diagnostic accuracy. The STARD initiative. Am J Clin Pathol 2003; 119(1): 18-22.

10 von Elm E, Altman DG, Egger M, Pocock SJ, Gøtzsche PC, Vandenbroucke JP. STROBE Initiative. The Strengthening the Reporting of Observational Studies in Epidemiology (STROBE) statement: guidelines for reporting observational studies. Epidemiology 2007; 18(6): 800-804.

11 Ferris FL 3rd, Kassoff A, Bresnick GH, Bailey I. New visual acuity charts for clinical research. Am J Ophthalmol 1982; 94: 91-96.

12 Cernea D, Răsceanu A, Bârjoveanu F, Berteanu C. Retinopathy in severe acute pancreatitis. Oftalmologia 2009; 53(3): 123-129.

13 Karoui El, Karras A, Lebrun G, Charles P, Arlet JB, Jacquot $\mathrm{C}$ et al. Thrombotic microangiopathy and purtscher-like retinopathy associated with adult-onset Still's disease: a role for glomerular vascular endothelial growth factor? Arthritis Rheum 2009; 61(11): 1609-1613

14 Krahulec B, Stefanicková J, Hlinst'áková S, Hirnerová E, Kosmálová V, Hasa J et al. Purtscher-like retinopathy-a rare complication of acute pancreatitis. Vnitr Lek 2008; 54(3): 276-281.

15 Sauer A, Nasica X, Zorn F, Petitjean P, Bader P, Speeg-Schatz C et al. Cryoglobulinemia revealed by a Purtscher-like retinopathy. Clin Ophthalmol 2007; 1(4): 555-557.

16 Stewart MW, Brazis PW, Guier CP, Thota SH, Wilson SD. Purtscher-like retinopathy in a patient with HELLP syndrome. Am J Ophthalmol 2007; 143(5): 886-887.

17 Okwuosa TM, Lee EW, Starosta M, Chohan S, Volkov S, Flicker $\mathrm{M}$ et al. Purtscher-like retinopathy in a patient with adult-onset Still's disease and concurrent thrombotic thrombocytopenic purpura. Arthritis Rheum 2007; 57(1): 182-185.

18 Holak HM, Holak S. Prognostic factors for visual outcome in Purtscher retinopathy. Surv Ophthalmol 2007; 52(1): 117118; with author reply 118-9.

19 Parc C. Purtscher-like retinopathy as an initial presentation of a thrombotic microangiopathy associated with antineoplastic therapy. Am J Hematol 2007; 82(6): 486-488.

20 Holak HM, Holak NH, Schenk C, Olinger A, Holak SA. [Correlation of retinal thickness with the extent of 
Purtscher's retinopathy]. Ophthalmologe 2006; 103(9): 798-805.

21 López-Tizón E, Reinoso-Montalvo C, Mencía-Gutiérrez E, Gutiérrez-Díaz E. Acute pancreatitis presenting as sudden blindness. Arch Soc Esp Oftalmol 2006; 81(3): 161-163.

22 Nayak H, Harun S, Palimar P. Purtscher's retinopathy after fracture dislocation of shoulder joint. Emerg Med J 2005; 22(11): 831-832.

23 Lai WW, Chen AC, Sharma MC, Lam DS, Pulido JS. Purtscher-like retinopathy associated with acute renal allograft rejection. Retina 2005; 25(1): 85-87.

24 Ong T, Nolan W, Jagger J. Purtscher-like retinopathy as an initial presentation of thrombotic thrombocytopenic purpura: a case report. Eye (Lond) 2005; 19(3): 359-361.

25 Castillo BV Jr, Khan AM, Gieser R, Shownkeen H. Purtscher-like retinopathy and Horner's syndrome following coil embolization of an intracavernous carotid artery aneurysm. Graefes Arch Clin Exp Ophthalmol 2005; 243(1): 60-62.

26 Kocak N, Kaynak S, Kaynak T, Oner HF, Cingil G. Unilateral Purtscher-like retinopathy after weight-lifting. Eur J Ophthalmol 2003; 13(4): 395-397.

27 Roncone DP. Purtscher's retinopathy. Optometry 2002; 73(3): 166-172.

28 Haq F, Vajaranant TS, Szlyk JP, Pulido JS. Sequential multifocal electroretinogram findings in a case of Purtscherlike retinopathy. Am J Ophthalmol 2002; 134(1): 125-128.

29 Lim BA, Ang CL. Purtscher-like retinopathy after retrobulbar injection. Ophthalmic Surg Lasers 2001; 32(6): 477-478.

30 Myers JP, Di Bisceglie AM, Mann ES. Cryoglobulinemia associated with Purtscher-like retinopathy. Am J Ophthalmol 2001; 131(6): 802-804

31 Zwolińska D, Medyńska A, Galar A, Turno A. Purtscherlike retinopathy in nephrotic syndrome associated with mild chronic renal failure. Pediatr Nephrol 2000; 15(1-2): 82-84.

32 Fumex L, Boizard Y, Burillon C, Denis P. Purtscher retinopathy in acute alcoholic pancreatitis. A case report. J Fr Ophtalmol 2004; 27(8): 927-931.

33 Voinea L, Totir M, Badarau A, Stana D, Pavel L, Panca A et al. Purtscher retinopathy-case report. Oftalmologia 2009; 53(2): 44-47.

34 Holak H, Holak N, Huzarska M, Holak S. [Pathogenesis of Purtscher's retinopathy and Purtscher-like retinopathy]. Klin Oczna 2007; 109(1-3): 38-45.

35 Schenk C, Holak H, Holak N, Olinger A. [Purtscher's syndrome. An example of a rare occurrence of ocular complication after thoracic compression trauma]. Unfallchirurg 2005; 108(2): 167-169.

36 Behrens-Baumann W, Scheurer G. [Purtscher disease. Range of variation of clinical manifestations in 11 patients and pathogenetic considerations]. Klin Monbl Augenheilkd 1991; 198(2): 99-107.

37 Fellinger C, Kunz R. [Unilateral Purtscher traumatic angiopathy]. Klin Monbl Augenheilkd 1986; 188(6): 599-600.

38 Zehetbauer G. [Pathogenesis of the traumatic retinal angiopathy "Purtscher"]. Klin Monbl Augenheilkd 1973; 163(2): 198-200.

39 Tenner A, Pape R, Genée E. [Fluorescence angiography and ophthalmodynamography in the late stage of Morbus Purtscher]. Klin Monbl Augenheilkd 1972; 160(1): 109-113.

40 Schmidt JG. [Traumatic retinal angiopathy (Purtscher) and fat embolism]. Klin Monbl Augenheilkd 1968; 152(5): 672-679.
41 -Justice J Jr, Lehmann RP. Cilioretinal arteries. Arch Ophthalmol 1976; 94(8): 1355-1358.

42 Chuang EL, Miller FS, Kalina RE. Retinal lesions following long bone fractures. Ophthalmology 1985; 92: 370-374.

43 Carrera CR, Pierre LM, Medina FM, Pierre P. Purtscher-like retinopathy associated with acute pancreatitis. Sao Paulo Med J 2005; 123(6): 289-291.

44 Sellami D, Ben Zina Z, Jelliti B, Abid D, Feki J, Chaâbouni M. Purtscher-like retinopathy in systemic lupus erythematosus. Two cases. J Fr Ophtalmol 2002; 25(1): 52-55.

45 Craddock PR, Hammerschmidt D, White JG, Dalmosso AP, Jacob HS. Complement (C5-a)-induced granulocyte aggregation in vitro. J Clin Invest 1977; 60(1): 260-264.

46 Marr WG, Marr EG. Some observations on Purtscher's disease. Am J Ophthalmol 1962; 54: 693.

47 Nautiyal A, Amescua G, Jameson A, Gradowski JF, Hong F, Doft B. Sudden loss of vision: Purtscher retinopathy in multiple myeloma. Can Med Assoc J 2009; 181(12): E277.

48 Harrison TJ, Abbasi CO, Khraishi TA. Purtscher retinopathy: an alternative etiology supported by computer fluid dynamic simulations. Invest Ophthalmol Vis Sci 2011; 52(11): 8102-8107.

49 Wang AG, Yen MY, Liu JH. Pathogenesis and neuroprotective treatment in Purtscher's retinopathy. Jpn J Ophthalmol 1988; 42-45.

50 Hammerschmidt DE, White JG, Craddock PR, Jacob HS. Corticosteroids inhibit complement-induced granulocyte aggregation. A possible mechanism for their efficacy in shock states. J Clin Invest 1979; 63(4): 798-803.

51 Bhan K, Ashiq A, Aralikatti A, Menon KV, McKibbin M. The incidence of Purtscher retinopathy in acute pancreatitis. $\mathrm{Br} J$ Ophthalmol 2008; 92(1): 151-153.

52 Blodi BA, Williams CA. Purtscher-like retinopathy after uncomplicated administration of retrobulbar anesthesia. Am J Ophthalmol 1997; 124(5): 702-703.

53 Alasil T, Tokuhara K, Bowes LD, Fan J. Purtscher-Like Retinopathy: Optical Coherence Tomography and Visual Field Findings. Ophthalmic Surg Lasers Imaging 2010; 9: 1-4.

54 Miguel A, Lopes N, Neves M, Andres R, Henriques F, Roque-Loureiro A. Purtscher's retinopathy with contralateral traumatic optic neuropathy - case report. Oftalmologia 2010; 34(2): 399-405.

55 Tajunisah I, Patel DK, Subrayan V. Purtscher retinopathy as an initial presentation of thrombotic thrombocytopenic purpura. J Thromb Thrombolysis 2010; 30(1): 112-113.

56 Sturm V, Menke MN, Landau K, Laube GF, Neuhaus TJ. Ocular involvement in paediatric haemolytic uraemic syndrome. Acta Ophthalmol 2010; 88(7): 804-807.

57 Bécheur H, Machevin L, Mostefa-Kara N, Zahedi R. Purtscher' ischemic retinopathy consecutive to an acute pancreatitis. Gastroenterol Clin Biol 2001; 25(10): 922-924.

58 Bui SK, O’Brien JM, Cunningham ET Jr. Purtscher retinopathy following drug-induced pancreatitis in an HIVpositive patient. Retina 2001; 21(5): 542-545.

59 Patel MR, Bains AK, O'Hara JP, Kallab AM, Marcus DM. Purtscher retinopathy as the initial sign of thrombotic thrombocytopenic purpura/hemolytic uremic syndrome. Arch Ophthalmol 2001; 119(9): 1388-1389.

60 Banach MJ, Williams GA. Purtscher retinopathy and necrotizing vasculitis with gemcitabine therapy. Arch Ophthalmol 2000; 118(5): 726-727.

61 Tabandeh H, Rosenfeld PJ, Alexandrakis G, Kronish JP, Chaudhry NA. Purtscher-like retinopathy associated with 
pancreatic adenocarcinoma. Am J Ophthalmol 1999; 128(5): 650-652.

62 Power MH, Regillo MC, Custis PH. Thrombotic thrombocytopenic purpura associated with Purtscher retinopathy. Arch Ophthalmol 1997; 115(1): 128-129.

63 Atabay C, Kansu T, Nurlu G. Late visual recovery after intravenous methylprednisolone treatment of Purtscher's retinopathy. Ann Ophthalmol 1993; 25(9): 330-333.
64 Schipper I. [Valsalva's maneuver: not always benign]. Klin Monbl Augenheilkd 1991; 198(5): 457-459.

65 Teichmann KD, Gronemeyer U. Unilateral morbus Purtscher with poor visual outcome. Ann Ophthalmol 1981; 13(11): 1295-1299.

66 Baarsma GS, van Balen TM. Purtscher's disease. Doc Ophthalmol 1977; 44(1): 95-104.

67 Tomasi LG, Rosman NP. Purtscher retinopathy in the battered child syndrome. Am J Dis Child 1975; 129(11): 1335-1337. 